\title{
A Pesquisa em Epidemiologia: Dificuldades e Perspectivas
}

Moisés Goldbaum*

A análise da pesquisa em epidemiologia remete ao enfrentamento das questões que cercam o desenvolvimento do campo científico e tecnológico em geral e o da saúde em particular. Assim sem entrar nas peculiaridades do campo, onde se pode demonstrar as suas deficiências bem como a sua importância da perspectiva de sua contribuição para o desenvolvimento da sociedade, pretende-se, nesse momento, visualizar aspectos que permitem entender os rumos trilhados na produção de conhecimentos em Epidemiologia.

Da mesma forma que o campo de C\&T em geral, os estudos em epidemiologia estão acompanhados de dilemas, falsos ou não. $O$ mais destacado deles refere-se ao aporte de recursos destinados à promoção da área. A escassez de recursos financeiros tem gerado uma crise marcante para $o$ avanço adequado das pesquisa científicas. Refletindo as crises econômicas identifica-se uma constante diminuição de recursos no apoio à produção acadêmica que, por sua vez e dada a sua aparente desvinculação e ausência de um expresso comprometimento social, se vê cada vez mais vulnerável a essas crises, determinando e reforçando uma desvalorização indevida desse campo.

Entretanto, o aporte e a origem de recursos financeiros não esgota os dilemas enfrentados pelos pesquisadores. A falsa oposição entre a produção acadêmica e a prestação de serviços constitue-se em questão que merece ser esclarecida. Esse falso dilema impede a visualização das diferentes vocações dessas duas instâncias de atuação e de suas complementariedades e intersecções. Desconhece-se, ou desconsidera-se, com freqüência, que cabe às estruturas acadêmicas responder mais diretamente à produção de conhecimentos, ou

* Professor Doutor do Depto de Medicina Preventiva da FMUSP Coordenador da Coordenação dos Institutos de Pesquisa - SES/SP 
seja o seu papel preponderante está mais voltado para a realização de pesquisas científicas, enquanto a área de serviços tem como finalidade precípua prestar cuidados de saúde demandados. Não se tratam de tarefas excludentes ou com valorização diferentes; pelo contrário, implicam atividades complementares correspondentes às suas diferentes atribuições. $O$ esclarecimento e a compreensão destas últimas permitem identificar os tipos e características da investigação científica desenvolvidas por essas instâncias, bem como determinar as necessidades a elas estabelecidas e, ainda, reconhecer os diferentes tempos necessários para o estabelecimento de adequadas respostas a essas necessidades. Da interação produtiva e conseqüente entre essas instâncias, determinada por um contínuo e estreito intercâmbio e fluxo de informações, pode-se encontrar elementos para o desenvolvimento mútuo das pesquisas, investigações e levantamentos epidemiológicos, evitando-se as duplicações de tarefas e prevenindo o desencadeamento de expectativas de difíceis possibilidades de alcançar sua plena realização.

De outro lado, outra questão nesse campo refere-se à definição de prioridades na condução do fomento às pesquisas. Sem entrar no mérito da esma, cuja abordagem implica em amplas polêmicas, trata-se de reconhecer a importância de identificar, no campo da Saúde Pública, a necessidade inerente de trabalharse com prioridades sanitárias. Isso não significa desobedecer, ou não levar em consideração, a lógica do desenvolvimento dos diferentes campos da ciência e, muito menos, menosprezar a criatividade e autonomia dos pesquisadores. Trata-se, em última instância, de buscar o ponto de articulação entre os diferentes setores sociais (no caso, o setor saúde e o setor técnico-científico), tornando o conhecimento mais disponível e aplicável às demandas da atualidade. Igualmente, permite a aproximação do trabalho científico aos embates sóciopolíticos que determinam e conduzem o desenvolvimento das sociedades.

A apresentação de alguns dados inéditos da produção científica na América Latina*, ainda em análise pela OPAS, permite uma primeira inspeção sobre o quadro vivido pela área nos últimos 20 anos. A exploração do banco de dados do ISI, ainda que superficial e passível de severas críticas de ordem técnica e metodológica, possibilita identificar alguns pontos que balizam os caminhos perseguidos pelo desenvolvimento científico e localizar-nos frente a ele.

A primeira informação, no campo da produção científica em geral, referese ao impacto gerado pela América Latina traduzido no fato de que pouco mais de $1 \%$ da produção mundial de publicações científicas provem dessa região. Trabalhando com 06 países latino-americanos (Argentina, Brasil, Chile, Cuba, México e Venezuela) verifica-se que eles respondem por cerca de $90 \%$ da produção científica geral da América Latina e, certamente, essa esti-

'Pellegrini Filho, A. e cols. dados inéditos 
mativa pode ser transposta para a área da saúde. A análise no período de 1973 a 1992 mostra um crescimento contínuo com alguns "acidentes" decorrentes da situação peculiar de cada país. Enquanto se observa um crescimento anual contínuo do número de publicações científicas, em revistas indexadas, provenientes de autores brasileiros, revela-se algumas quedas periódicas na Argentina, motivadas possivelmente pela situação sócio-política vivida por aquele país e que atingiu mais acentuadamente o campo das disciplinas biomédicas. Vale lembrar que os dois (Brasil e Argentina) respondem por cerca de $1 / 3$ da produção desses 06 países. De outro lado, a Argentina que detinha a liderança, em termos absolutos, do número de publicações, viu-se superada pelo Brasil a partir de 1978 .

Vista da perspectiva disciplinar, nota-se um predomínio crescente da produção biomédica, que no último decênio respondeu por $46.5 \%$ das publicações do setor saúde, contra $39.7 \%$ do decênio anterior. Ainda que na região a clínica ainda seja predominante, no Brasil essa situação já se inverteu, vindo a demonstrar a tendência de dirigir-se a atenção científica para as bases moleculares da ocorrência da doença. Em relação à saúde pública, registra-se que somente $3.2 \%$ dos artigos são originários desse campo, indicando a pequena importância e prioridade que lhe é conferida.

Uma análise de 95 artigos em epidemiologia provenientes desses 06 países, e publicados na literatura internacional (excluídos os periódicos nacionais) nesse período, mostra uma alta concentração dos mesmos no Brasil (66\%). Cumpre destacar que esses artigos, ao contrário do que se observa na produção dos países do chamado $1^{\circ}$ Mundo, onde predominam o estudo das doenças crônicas, preocupam-se quase totalmente (cerca de 96\%) com problemas materno-infantis e doenças infecciosas e parasitárias. Embora possam estar a traduzir a adequação dos estudos epidemiológicos às prioridades e especificidades dos nossos países, podem igualmente estar revelando a falta de acompanhamento dos novos problemas que marcam a modernização das sociedades.

\section{Bibliografia}

1. GARFIELD, E. Publication and national research policies In: International Seminar on the Challenges of the Information Era: Agents and Users. São Paulo, 1994. 